\title{
Occult Esophageal Squamous Cell Carcinoma Presenting with Multiple Bony Osteolytic Lesions Clinically Mimicking Multiple Myeloma: A Diagnostic Dilemma
}

\author{
Bifica Sofia Lyngdoh ${ }^{1} \quad$ Biswajit Dey ${ }^{1} \quad$ Vandana Raphael $^{1} \quad$ ladarilang Tiewsoh ${ }^{2}$
}

\author{
${ }^{1}$ Department of Pathology, North Eastern Indira Gandhi Regional \\ Institute of Health and Medical Sciences, Shillong, Meghalaya, \\ India \\ 2Department of General Medicine, North Eastern Indira Gandhi \\ Regional Institute of Health and Medical Sciences, Shillong, India \\ J Lab Physicians:2020;12:76-78
}

\author{
Address for correspondence Biswajit Dey, MD, Department of \\ Pathology, North Eastern Indira Gandhi Regional Institute of Health \\ and Medical Sciences, Shillong, Meghalaya 793018, India \\ (e-mail: drbish25@rediffmail.com).
}

\author{
Abstract \\ Keywords \\ - esophageal squamous \\ cell carcinoma \\ - dysphagia \\ - multiple myeloma
}

Bone metastasis as an initial presentation of esophageal carcinoma is uncommon. In the absence of typical presentations like dysphagia, these cases may lead to diagnostic dilemmas both for the clinicians and pathologists. Here, we report a case of disseminated metastasis of esophageal squamous cell carcinoma to the bone in a 47-year-old female, who presented with multiple osteolytic lesions and clinically mimicking multiple myeloma. A detailed diagnostic work-up established the diagnosis of esophageal squamous cell carcinoma.

\section{Introduction}

Esophageal cancer is one of the fatal cancers worldwide with a 5 -year survival rate of $40 \%$ for localized tumors and $4 \%$ for tumors with advanced distal metastasis. ${ }^{1}$ Histological types, grade, and stage are important factors in esophageal cancer prognosis. Regional and distant metastases have a profound impact on survival and outcome. ${ }^{1}$ The most common sites of esophageal cancer metastases are lymph nodes, lung, liver, bones, adrenal glands, and brain. ${ }^{1}$ Although bone metastasis of esophageal carcinoma is known, metastasis to the bone as an initial presentation is uncommon. ${ }^{2,3}$ Bone metastasis of esophageal carcinoma presenting with osteolytic lesions may clinically mimic multiple myeloma (MM) leading to delay in diagnosis. ${ }^{3}$ Here, we present a case of disseminated metastasis of esophageal squamous cell carcinoma (ESCC) to the bone in a 47-year-old female, who presented with multiple osteolytic lesions, clinically mimicking MM.

\section{Case Report}

A 47-year-old female was admitted to hospital with an abrupt onset of left forearm pain with limited range of motion in the left hand. She had 6-month history of generalized weakness, decreased appetite, and backache. There was no history of trauma. She had no other significant past history.

On examination, her vitals were stable. She had pronounced lumbar kyphoscoliosis. No other peripheral lymphadenopathy or any organomegaly was detected. The rest of the systemic and general physical examinations were unremarkable.

The patient was found to have anemia with hemoglobin of $7.7 \mathrm{~g} / \mathrm{dL}$ with normocytic normochromic morphology of the red blood cells, deranged renal parameters with a creatinine of $2.8 \mathrm{mg} / \mathrm{dL}$, and hypercalcemia with a corrected calcium level of $16.8 \mathrm{mg} / \mathrm{dL}$. The parathyroid hormone level was $20.2 \mathrm{pg} / \mathrm{mL}$, which was normal. The Mantoux test was negative. Her skeletal survey revealed a pathological fracture of left humerus with multiple lytic lesions in the skull, dorso-lumbar vertebrae, and iliac bones ( - Fig. 1A-C). A provisional diagnosis of MM was maintained after ruling out hyperparathyroidism.

The bone marrow aspirate was diluted; however, it showed an increase in plasma cells. Serum electrophoresis did not reveal any monoclonal peak. Bence Jones protein was not detected in the urine. At this point, the diagnosis of MM was in doubt. Bone marrow biopsy revealed myelofibrosis with infiltration

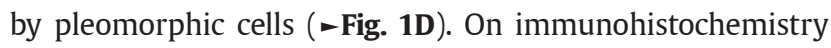

DOI https://doi.org/

10.1055/s-0040-1714193

ISSN 0974-2727.
C2020 by The Indian Association of Laboratory Physicians
License terms

(ㅇ) (1) $\ominus \circledast$ 


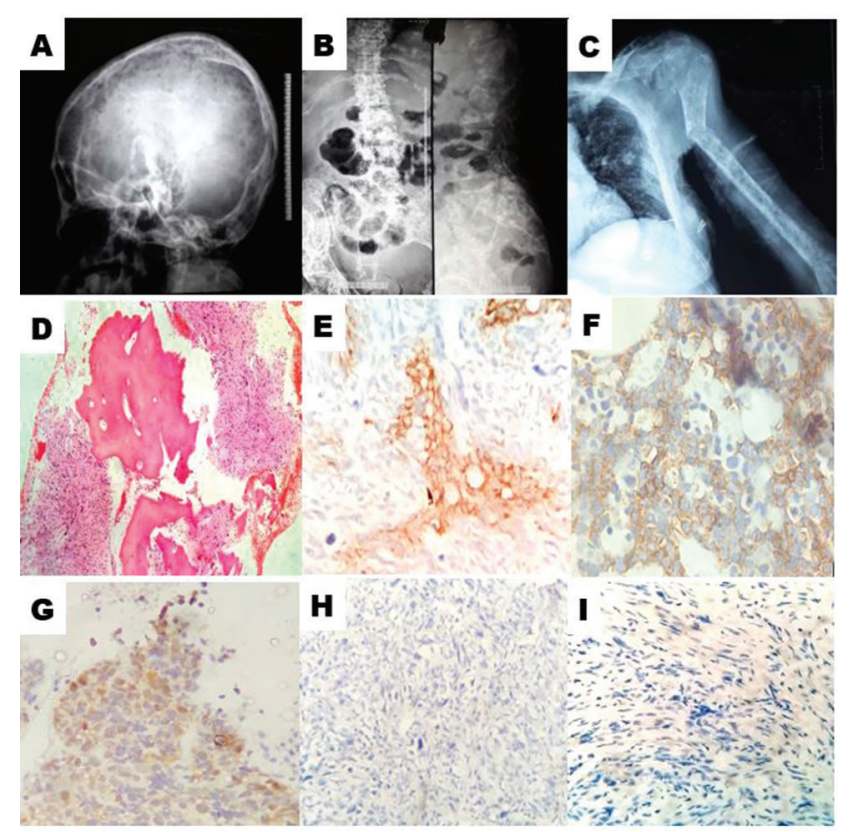

Fig. 1 Multiple lytic lesions of the (A) skull, (B) dorso-lumbar vertebrae and iliac bones. (C) Fracture left humerus. (D) Bone marrow biopsy showing myelofibrosis with infiltration by pleomorphic cells $(\mathrm{H}$ and $\mathrm{E}, 4 \times)$. The pleomorphic cells positive for cytokeratin AE1/AE2 (E), CK5/6 (F), and p63 (G) (IHC, 400x) and negative for CD38 (H) and CD138 (I) (IHC, 400×). IHC, immunohistochemistry.

(IHC), these cells were positive for cytokeratin AE1/AE2, CK5/6, CK7, and p63 ( - Fig. 1E-G). The tumor cells were negative for CK20, CD45, CD38, and CD138 ( $\boldsymbol{- F i g . ~ 1 H , I ) . ~ B a s e d ~ o n ~ t h e s e ~}$ findings a diagnosis of poorly differentiated carcinoma metastasis to bone marrow from the upper gastrointestinal tract was made. Upper gastrointestinal endoscopy revealed an esophageal ulcer measuring $2 \times 1 \mathrm{~cm}$, which was 20 to $22 \mathrm{~cm}$ from the upper incisors. Histopathological examination of the biopsy from the esophageal ulcer showed features suggestive of poorly differentiated squamous cell carcinoma ( - Fig. $2 \mathrm{~A}$ ). The tumor cells were positive for cytokeratin ( - Fig. 2B). Thus, a final diagnosis of a disseminated bone marrow metastasis from ESCC was made. In the meantime, the general condition of the patient deteriorated rapidly, and she expired after 4 weeks of hospital admission.

\section{Discussion}

ESCC, which is a predominant histologic subtype of esophageal cancer, has an overall 5-year survival rate of $14 \%{ }^{4}$ Metastases of ESCC to the bone are uncommon and vary from 1 to $14 \%$ in autopsy series. ${ }^{5}$ In clinical practice, bone metastases of esophagus cancer occurred infrequently. Radiologically bone metastases in esophageal carcinoma are detected in $1.6 \%$ of all cases with distant metastases. ${ }^{5}$ The detection rate has improved with positron emission tomography using F-18 FDG (fludeoxyglucoseF18 injection). ${ }^{5}$ Micrometastases of esophageal carcinoma to bone marrow are detected in $20.9 \%$ of the cases by light microscopic examination and $30.2 \%$ of cases by cytokeratin IHC. ${ }^{2}$ Usually

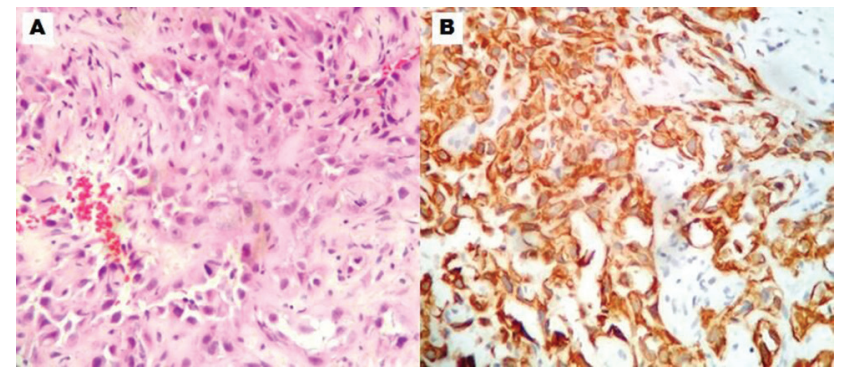

Fig. 2 (A) Esophageal biopsy showing esophageal squamous cell carcinoma (H \& E, 400×). (B) Tumor cells positive for cytokeratin (IHC, 400×). IHC, immunohistochemistry.

bone metastases are osteolytic in nature, mixed patterns like osteolytic-osteoblastic and osteolytic-osteosclerotic are also reported. ${ }^{3,5}$

The various other malignancies, which present with osteolytic metastases, are malignant melanoma, renal cell carcinoma, gastric carcinoma, colorectal carcinoma, hepatocellular carcinoma, thyroid carcinoma, and small cell lung carcinoma. ${ }^{3}$ Like other malignancies, spine is the most common site of bone metastases in esophageal carcinoma. ${ }^{5}$ In the present case, a panel of IHC markers helped in ruling out other malignancies. The tumor cells in the bone marrow biopsy were negative for HMB45 (ruled out malignant melanoma), CD10 (ruled out renal cell carcinoma), CK20 (ruled out colorectal carcinoma), HepPar1 (ruled out hepatocellular carcinoma), and thyroid transcription factor-1 or TTF1 (ruled out thyroid carcinoma). Negative immunoreactivity for leukocyte common antigen ruled out lymphoma whereas negative immunoreactivity for CD38 and CD138 ruled out plasma cell dyscrasia like MM. Infections like tuberculosis can also present with osteolytic bony lesions. ${ }^{3}$ In the present case, tuberculosis was ruled out as there was no fever and the Mantoux test was negative.

The natural course of esophageal carcinoma involves the esophagus primarily with extension to the adjacent structures. ${ }^{6}$ So, the symptoms appear when these anatomical structures are involved leading to dysphagia, dysphonia from laryngeal paralysis, weight loss followed by substernal and/ or epigastric pain, and regurgitation. ${ }^{6}$ Dysphagia is a typical presentation of esophageal carcinoma present in more than $80 \%$ of the cases. ${ }^{6,7}$ However, dysphagia occurs only when two-thirds of the esophageal lumen is involved. ${ }^{7}$ A deep infiltrating tumor can metastasize to adjacent organs without producing dysphagia. ${ }^{3}$ Cases of esophageal carcinoma presenting with bone pain due to bone metastasis and without any complaint of dysphagia are extremely rare. ${ }^{5}$ The lack of dysphagia in the present case could be explained by the nonstenotic pattern of the lesion. Comparison of the present case with some of the cases reported in the literature is enumerated in - Table $1.3 .5-9$

Cases of occult carcinomas presenting with osteolytic bone metastasis may clinically mimic MM. ${ }^{3}$ The diagnosis of $\mathrm{MM}$ requires the presence of $\geq 10 \%$ clonal plasma cells in the bone marrow or biopsy proven plasmacytoma along with evidence of end-organ damage such as hyper 
Table 1 Table showing comparison of the present case with some of the cases reported in the literature

\begin{tabular}{|c|c|c|c|c|}
\hline Authors & Age $(y) /$ sex & $\begin{array}{l}\text { Histological type of } \\
\text { esophageal carcinoma }\end{array}$ & $\begin{array}{l}\text { Site(s) of bony } \\
\text { metastasis }\end{array}$ & $\begin{array}{l}\text { Nature of bone } \\
\text { metastasis }\end{array}$ \\
\hline Alvarez Diaz et al ${ }^{3}$ & $59 / M$ & Adenocarcinoma & $\begin{array}{l}\text { Cervical and dorso-lum- } \\
\text { bar vertebrae, left } \\
\text { humerus, ribs and right } \\
\text { femoral neck }\end{array}$ & $\begin{array}{l}\text { Osteolytic and } \\
\text { osteoblastic }\end{array}$ \\
\hline \multirow[t]{5}{*}{ Reezae and Bradaran Rahimi ${ }^{5}$} & $60 / F$ & ESCC & Left femur & Osteolytic \\
\hline & $42 / F$ & ESCC & Left tibia & Osteolytic \\
\hline & $24 / \mathrm{M}$ & ESCC & Left iliac bone & Osteolytic \\
\hline & $60 / F$ & ESCC & Cervical vertebrae & Osteolytic \\
\hline & $40 / \mathrm{M}$ & ESCC & Ribs & Osteolytic-sclerotic \\
\hline Shewchuk et al ${ }^{6}$ & $59 / F$ & ESCC & $\begin{array}{l}\text { Right femur, left iliac } \\
\text { bone, and skull }\end{array}$ & Osteolytic \\
\hline Viaro et $\mathrm{al}^{7}$ & $58 / \mathrm{M}$ & Epidermoid carcinoma & Cervical vertebrae & Osteolytic \\
\hline Singh et a ${ }^{8}$ & $37 / M$ & $\begin{array}{l}\text { ESCC (post esophagec- } \\
\text { tomy for ESCC) }\end{array}$ & Right calcaneus & Osteolytic \\
\hline Sánchez-Jiménez et al ${ }^{9}$ & $63 / \mathrm{M}$ & Adenocarcinoma & Left maxilla & Osteolytic \\
\hline Present case & $47 / F$ & ESCC & $\begin{array}{l}\text { Skull, dorso-lumbar ver- } \\
\text { tebrae iliac bones, and } \\
\text { left humerus }\end{array}$ & Osteolytic \\
\hline
\end{tabular}

Abbreviation: ESCC, esophageal squamous cell carcinoma.

Calcemia, Renal dysfunction, unexplained Anemia, and Bone lytic lesions (CRAB). ${ }^{10}$ There are reports of MM presenting with an esophageal ulcer. ${ }^{10}$ The present case had features of end-organ damage like hypercalcemia, renal dysfunction, anemia, and bony lytic lesions, which led to the clinical suspicion of MM. Bone marrow biopsy with negative monoclonal peak and urine Bence Jones protein helped in ruling out MM. Upper gastrointestinal endoscopy and biopsy from the esophageal ulcer helped in confirming the diagnosis of ESCC.

Such cases are managed symptomatically as chemotherapy and radiotherapy do not improve survival. ${ }^{3}$

Occult esophageal carcinoma presenting with osteolytic bone metastasis may clinically mimic MM. Typical clinical presentations like dysphagia, dysphonia, substernal and/or epigastric pain, and regurgitation may not be present in these cases leading to diagnostic dilemma both for the clinicians and pathologists.

\section{Conflict of Interest}

None declared.

\section{References}

1 Shaheen O, Ghibour A, Alsaid B. Esophageal cancer metastases to unexpected sites: a systematic review. Gastroenterol Res Pract 2017;2017:1657310

2 Bagheri R, Maddah G, Saedi HS, Sadeghian MH, Roodbari S. Bone marrow involvement in esophageal cancer patients who underwent surgical resection. Eur J Cardiothorac Surg 2011;40(2):343-346
3 Alvarez Díaz H, Aznar MU, Afonso FJ. Bone lesions simulating multiple myeloma: unusual presentation of esophageal cancer. Eur J Intern Med 2009;20(1):e14

4 Dey B, Raphael V, Khonglah Y, Lynrah KG. Immunohistochemical analysis of P53 and PRB in esophageal squamous cell carcinoma. J Clin Diagn Res 2014;8(5):FC01-FC03

5 Reezae H, Bradaran Rahimi M. Squamous cell carcinoma of esophagus presenting as bone metastases in five cases. Iran J Otorhinolaryngol 2007;19:9-14

6 Shewchuk SM, Meneses BO, Lerma LB, Shnider BI. Femoral and skull metastasis with hypercalcemia: occurrence with esophageal carcinoma without dysphagia. Arch Intern Med 1982;142(12):2207-2209

7 Viaro AL, Roballo CA, de Campos PT, Teixeira CO, Teixeira MAB. Occult esophageal squamous cell carcinoma with metastases to the spine and central nervous system. Autops Case Rep 2015;5(1):33-37

8 Singh HK, Silverman JF, Ballance WA Jr, Park HK. Unusual small bone metastases from epithelial malignancies: diagnosis by fine-needle aspiration cytology with histologic confirmation. Diagn Cytopathol 1995;13(3):192-195

9 Sánchez-Jiménez J, Acebal-Blanco F, Arévalo-Arévalo RE, Molina-Martínez M. Metastatic tumours in upper maxillary bone of esophageal adenocarcinoma. A case report. Med Oral Patol Oral Cir Bucal 2005;10(3):252-257

10 Pehlivan Y, Sevinc A, Sari I, et al. An interesting cause of esophageal ulcer etiology: multiple myeloma of IgG kappa subtype. World J Gastroenterol 2006;12(14):2305-2307 